\title{
CALCULATING THE POSITRON - ELECTRON CORRELATION ENERGY IN ZnO WITH THE MODIFIED SINGLE WAVE FUNCTION FOR POSITRON
}

\author{
Chau Van Tao ${ }^{(1)}$, Trinh Hoa Lang ${ }^{(1)}$, \\ Nguyen Anh Tuan ${ }^{(2)}$, Le Hoang Chien ${ }^{(1)}$, Nguyen Huu Loc ${ }^{(1)}$ \\ (1) University of Science \\ (2) Research and Development Center for Radiation Technology
}

ABSTRACT: The ZnO - positron system is studied and its positron - electron correlation energy is estimated in its ground state. The positron binds with the outer shell electrons of Zinc and Oxigen to form the pseudo $\mathrm{ZnO}$ - positron molecule before it anihilates with one of these electrons. In this work, the single wave function for positron is modified according to the principle of linear superposition, and by using Variational Quantum Monte - Carlo method (VQMC) the correlation energy of this system is estimated with the value $E_{c}^{e-p}=-9.3 \pm 1.1 \mathrm{eV}$. It turns out that the value is closer to results estimated by other methods than the value that we had done before.

Keywords: Positron, Variational Quantum Monte - Carlo

\section{INTRODUCTION}

There are many methods that have been used to estimate the positron-electron correlation energy [2]. In the article, we use the VQMC method to estimate the positronelectron correlation energy. The method is more successful when we make the form of the trial wave functions of particles in a considered system are loser to that of the exact wave function. So, our main aim is to modify the form of the trial wave function of the positron.

\section{THEORY}

\section{Variational Quantum Monte Carlo method}

The quantum mechanical system is represented by an exact wave function $\psi(R)$ and the average value of the system's energy (we want to get the quantity in the process of estimating the electron, positron correlation energy of the zinc oxide - positron system) is given by

$$
\langle\mathrm{H}\rangle=\frac{\int \mathrm{dR} \psi^{*}(\mathrm{R}) \mathrm{H}(\mathrm{R}) \psi(\mathrm{R})}{\int \mathrm{dR} \psi^{*}(\mathrm{R}) \psi(\mathrm{R})}
$$

However, we cannot properly construct the form of the exact wave function. This also means that we cannot exactly calculate $\mathrm{H}(\mathrm{R})$ in theory. Therefore, we must choose a trial total wave function $\psi_{\mathrm{T}}(\mathrm{R}, \alpha)$ that depends on a set of parameters $\alpha$. In the circumstance, we define two new quantities

$$
\rho(\mathrm{R}, \alpha)=\frac{\left|\psi_{\mathrm{T}}(\mathrm{R}, \alpha)\right|^{2}}{\int \mathrm{dR}\left|\psi_{\mathrm{T}}(\mathrm{R}, \alpha)\right|^{2}}=\left|\psi_{\mathrm{T}}(\mathrm{R}, \alpha)\right|^{2}
$$




$$
\mathrm{E}(\mathrm{R}, \alpha)=\frac{\mathrm{H}(\mathrm{R}) \psi_{\mathrm{T}}(\mathrm{R}, \alpha)}{\psi_{\mathrm{T}}(\mathrm{R}, \alpha)}
$$

With combining (1), (2) and (3) we can figure out the equation (4)

$$
\langle\mathrm{E}\rangle=\frac{\int \mathrm{dR} \rho(\mathrm{R}, \alpha) \frac{\mathrm{H}(\mathrm{R}) \psi_{\mathrm{T}}(\mathrm{R}, \alpha)}{\psi_{\mathrm{T}}(\mathrm{R}, \alpha)}}{\int \mathrm{dR} \psi_{\mathrm{T}}{ }^{*}(\mathrm{R}, \alpha) \psi_{\mathrm{T}}(\mathrm{R}, \alpha)}
$$

can approach $\langle\mathrm{H}\rangle$ only if the trial wave function is close to the exact wave function. To satisfy this condition, we can vary values of $\alpha$ and search for the minimum value of $\langle E\rangle$ which corresponds to the exact wave function. The calculations are solved by using techniques from the Variational Quantum Monte Carlo method.

\section{Model of the zinc oxide - positron}

In this paper, the electron, positron correlation - energy of the zinc oxide - positron system which shown in figure 1 is estimated by applying to the VMC method in which the Hamiltonian and the trial total wave function were used.

With the Born - Oppenheimer approximation [3], the Hamiltonian for the system is then

$$
\begin{aligned}
\mathrm{H}= & -\frac{1}{2} \sum_{\mathrm{i}=1}^{6} \nabla_{\mathrm{i}}^{2}-\frac{1}{2} \nabla_{\mathrm{p}}^{2}+\frac{1}{2} \sum_{\mathrm{i}=1}^{6} \sum_{\substack{\mathrm{j}=1 \\
\mathrm{j} \neq \mathrm{i}}}^{6} \frac{1}{\left|\mathrm{r}_{\mathrm{i}}-\mathrm{r}_{\mathrm{j}}\right|}+\frac{1}{2} \frac{\mathrm{Z}_{\mathrm{Zn}} \mathrm{Z}_{\mathrm{O}}}{\left|\mathrm{d}_{\mathrm{Zn}}-\mathrm{d}_{\mathrm{O}}\right|}+\frac{1}{2} \frac{\mathrm{Z}_{\mathrm{Zn}} \mathrm{Z}_{\mathrm{O}}}{\left|\mathrm{d}_{\mathrm{Zn}}-\mathrm{d}_{\mathrm{O}}\right|} \\
& -\sum_{\mathrm{i}=5}^{6} \frac{\mathrm{Z}_{\mathrm{Zne}}}{\left|\mathrm{r}_{\mathrm{iZn}}\right|}-\sum_{\mathrm{i}=1}^{4} \frac{\mathrm{Z}_{\mathrm{Oe}}}{\left|\mathrm{r}_{\mathrm{iO}}\right|}+\frac{\mathrm{Z}_{\mathrm{Znp}}}{\left|\mathrm{r}_{\mathrm{pZn}}\right|}+\frac{\mathrm{Z}_{\mathrm{Op}}}{\left|\mathrm{r}_{\mathrm{pO}}\right|}-\sum_{\mathrm{i}=1}^{6} \frac{1}{\left|\mathrm{r}_{\mathrm{ip}}\right|}
\end{aligned}
$$

where

$-\quad-\frac{1}{2} \nabla_{\mathrm{i}}^{2},-\frac{1}{2} \nabla_{\mathrm{p}}^{2}$ is alternatively the kinetic operators of the i-th electron and the positron.

- $r_{\mathrm{iZn}}\left(\mathrm{r}_{\mathrm{iO}}\right)$ is the distance from the position of the i-th electron to the position of zinc atom (oxygen atom).

- $r_{\mathrm{pZn}}\left(\mathrm{r}_{\mathrm{pO}}\right)$ is the distance from the position of the positron to the position of zinc atom (oxygen atom). Similarly, $r_{i p}$ is the distance from the position of the i-th electron to the position of the positron.

- $r_{i}\left(r_{j}\right)$ is the distance from the position of the $\mathrm{i}$-th (j-th) electron to the coordinate angle.

- $d_{Z n}\left(d_{O}\right)$ is the distance from the position of zinc atom (oxygen atom) to the coordinate angle.

- $Z_{\mathrm{Zne}}\left(\mathrm{Z}_{\mathrm{Oe}}\right)$ is the effective nuclear charge of zinc (oxygen) atom for the electrons.

- $Z_{\mathrm{Znp}}\left(\mathrm{Z}_{\mathrm{Op}}\right)$ is the effective nuclear charge of zinc (oxygen) atom for the positron. 
$Z_{O}$ is the effective nuclear charge of oxygen atom for zinc atom. Conversely, $\mathrm{Z}_{\mathrm{Zn}}$ is the nuclear charge of zinc atom for oxygen atom.

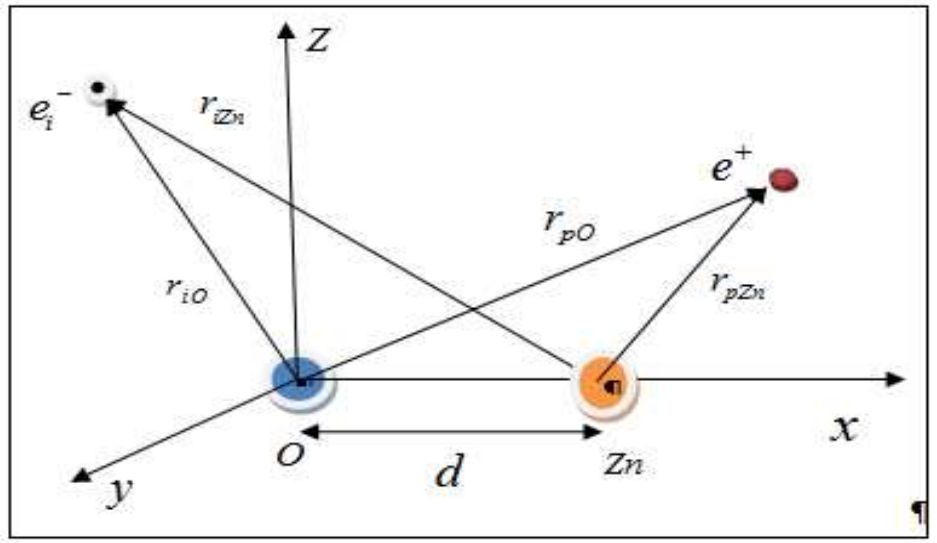

Fig.1. The schematic of the zinc oxide - positron system

The trial total wave function for the system used in this work is a product of single particle wave functions multiplied by a Jastrow factor (an exponent of many particle correlation factors)

$\psi_{\mathrm{T}}=\prod_{\mathrm{i}=1}^{4} \psi_{\mathrm{io}} \prod_{\mathrm{i}=1}^{2} \psi_{\mathrm{iZn}} \prod_{\substack{\mathrm{i} i=1 \\ \mathrm{j}>\mathrm{i}}}^{6} \psi^{\mathrm{e}-\mathrm{e}}{ }_{\mathrm{ij}} \prod_{\mathrm{i}=1}^{6} \psi_{\mathrm{ip}}^{\mathrm{e}-\mathrm{p}} \psi_{\mathrm{p}}$

with

- $\quad \psi_{\mathrm{iO}}$ is the single - particle wave function for the i-th electron belonging to oxygen atom. With the Slater's approach [4], it takes the following form

$-\quad \psi_{\mathrm{iO}}=\mathrm{N}_{\mathrm{O}} \mathrm{r}_{\mathrm{iO}} \mathrm{e}^{-\lambda_{\mathrm{O}} \mathrm{r}_{\mathrm{iO}}}+\mathrm{N}_{\mathrm{O}} \mathrm{r}_{\mathrm{iZn}} \mathrm{e}^{-\lambda_{\mathrm{Zn}} \mathrm{r}_{\mathrm{ZZn}}}$

- $\quad \psi_{\mathrm{iZn}}$ is the single - particle wave function for the i-th electron belonging to zinc atom. With the Slater's approach, it takes the following form

- $\psi_{\mathrm{iZn}}=\mathrm{N}_{\mathrm{Zn}} \mathrm{r}^{4}{ }_{\mathrm{iZn}} \mathrm{e}^{-\lambda_{\mathrm{Zn}} \mathrm{r}_{\mathrm{Zn}}}+\mathrm{N}_{\mathrm{Zn}} \mathrm{r}^{4}{ }_{\text {io }} \mathrm{e}^{-\lambda_{\mathrm{o}} \mathrm{r}_{\mathrm{io}}}(8)$
- $\quad \psi_{\mathrm{ij}}^{\mathrm{e}-\mathrm{e}}$ is the Jastrow factor that reflects the correlation between the i-th electron and the j-th electron. With the Pade's approach [1], it takes the form

$-\quad \psi_{i j}^{\mathrm{e} e}=\mathrm{e}^{\frac{\beta \mathrm{r}_{\mathrm{j}}}{1+\alpha \mathrm{rij}_{\mathrm{ij}}}}$

- $\quad \psi_{\mathrm{ip}}^{\mathrm{e}-\mathrm{p}}$ is the Jastrow factor that reflects the correlation between the i-th electron and the positron. With the Pade's approach, it takes the form

$$
-\quad \psi^{\mathrm{e}-\mathrm{p}}{ }_{\mathrm{ip}}=\mathrm{e}^{\frac{\beta_{\mathrm{rip}}}{1+\alpha_{\mathrm{ip}}}}
$$

- $\psi_{\mathrm{p}}$ is the single - particle wave function for the positron. When the positron moves into Zinc oxide molecule, the positron may belong to either zinc atom or oxygen atom. So, we assume that positron exists in some allowed state supported by either the nucleus of Zinc atom or the nucleus of oxygen atom. According to the principle 
of linear superposition, the single particle wave function for positron takes form

$\psi_{\mathrm{p}}=\frac{1}{2} \mathrm{~N}_{\mathrm{p}} \mathrm{r}_{\mathrm{pO}} \mathrm{e}^{-\lambda_{\mathrm{po}} \mathrm{r}_{\mathrm{pO}}}+\frac{1}{2} \mathrm{~N}_{\mathrm{p}} \mathrm{r}_{\mathrm{pZn}}^{4} \mathrm{e}^{-\lambda_{\mathrm{pZn}} \mathrm{r}_{\mathrm{pZn}}}$
Applying the Hamiltonian in eq. (5) to eq.(6), the total energy takes the following form:

$$
E=\sum_{i=1}^{6}\left(2 K_{i}-F_{i}^{2}\right)+2 K_{p}-F_{p}^{2}+V
$$

where

$$
\begin{aligned}
& \mathrm{K}_{\mathrm{i}}=-\frac{1}{4} \nabla_{\mathrm{i}}^{2} \ln \psi_{\mathrm{T}}=-\frac{1}{4}\left[\nabla_{\mathrm{i}}^{2}\left(\ln \varphi_{\mathrm{e}}\right)+\nabla_{\mathrm{i}}^{2}\left(\sum_{\substack{\mathrm{j}=1 \\
\mathrm{j} \neq \mathrm{i}}}^{6} \ln \psi_{\mathrm{ij}}^{\mathrm{e}-\mathrm{e}}\right)+\nabla_{\mathrm{i}}^{2}\left(\ln \psi_{\mathrm{ip}}^{\mathrm{e}-\mathrm{p}}\right)\right] \\
& \mathrm{F}_{\mathrm{i}}=\frac{1}{\sqrt{2}} \overrightarrow{\nabla_{\mathrm{i}}} \ln \psi_{\mathrm{T}}=\frac{1}{\sqrt{2}}\left(\overrightarrow{\nabla_{\mathrm{i}}} \ln \varphi_{\mathrm{e}}+\vec{\nabla}_{\mathrm{i}} \sum_{\substack{\mathrm{j}=1 \\
\mathrm{j} \neq \mathrm{i}}}^{6} \ln \left(\psi_{\mathrm{ij}}^{\mathrm{e}-\mathrm{e}}\right)+\overrightarrow{\nabla_{\mathrm{i}}} \ln \left(\psi_{\mathrm{ip}}^{\mathrm{e}-\mathrm{p}}\right)\right] \\
& \mathrm{K}_{\mathrm{p}}=-\frac{1}{4} \nabla_{\mathrm{p}}^{2} \ln \psi_{\mathrm{T}}=-\frac{1}{4}\left[\nabla_{\mathrm{p}}^{2}\left(\ln \psi_{\mathrm{p}}\right)+\nabla_{\mathrm{p}}^{2}\left(\sum_{\mathrm{i}=1}^{6} \ln \psi_{\mathrm{ip}}^{\mathrm{e}-\mathrm{p}}\right)\right] \\
& \mathrm{F}_{\mathrm{p}}=\frac{1}{\sqrt{2}} \vec{\nabla}_{\mathrm{p}} \ln \psi_{\mathrm{T}}=\frac{1}{\sqrt{2}}\left(\overrightarrow{\nabla_{\mathrm{p}}}\left(\sum_{\mathrm{i}=1}^{6} \ln \left(\psi_{\mathrm{ip}}^{\mathrm{e}-\mathrm{p}}\right)\right)+\vec{\nabla}_{\mathrm{p}} \ln \left(\psi_{\mathrm{p}}\right)\right) \\
& \mathrm{V}=\frac{\mathrm{Z}_{\mathrm{Zn}} \mathrm{Z}_{\mathrm{O}}}{\left|\mathrm{d}_{\mathrm{Zn}}-\mathrm{d}_{\mathrm{O}}\right|}+\frac{1}{2} \sum_{\mathrm{i}=1}^{6} \sum_{\mathrm{j} \neq 1}^{6} \frac{1}{\left|\mathrm{r}_{\mathrm{i}}-\mathrm{r}_{\mathrm{j}}\right|}-\sum_{\mathrm{i}=5}^{6} \frac{\mathrm{Z}_{\mathrm{Zne}}}{\left|\mathrm{r}_{\mathrm{iZn}}\right|}-\sum_{\mathrm{i}=1}^{4} \frac{\mathrm{Z}_{\mathrm{Oe}}}{\left|\mathrm{r}_{\mathrm{iO}}\right|}+\frac{\mathrm{Z}_{\mathrm{Znp}}}{\left|\mathrm{r}_{\mathrm{pZn}}\right|}+\frac{\mathrm{Z}_{\mathrm{Op}}}{\left|\mathrm{r}_{\mathrm{pO}}\right|}-\sum_{\mathrm{i}=1}^{6} \frac{1}{\left|\mathrm{r}_{\mathrm{ip}}\right|}
\end{aligned}
$$

The form of the electron, positron correlation energy which is extract from (12) is as then

$$
E^{e-p}=\sum_{i=1}^{6}\left(2 K_{i}^{e-p}-\left(F_{i}^{e-p}\right)^{2}\right)+2 K_{p}^{e-p}-\left(F_{p}^{e-p}\right)^{2}
$$

where

$$
\mathrm{K}_{\mathrm{i}}^{\mathrm{e} \_\mathrm{p}}=-\frac{1}{4} \nabla_{\mathrm{i}}^{2}\left(\ln \psi_{\mathrm{ip}}^{\mathrm{e} \_\mathrm{p}}\right) \text { and } \mathrm{K}_{\mathrm{p}}^{\mathrm{e} \_\mathrm{p}}=-\frac{1}{4} \nabla_{\mathrm{p}}^{2}\left(\sum_{\mathrm{i}=1}^{6} \ln \psi_{\mathrm{ip}}^{\mathrm{e} \_\mathrm{p}}\right)
$$




$$
\begin{aligned}
\left(\mathrm{F}_{\mathrm{i}}^{\mathrm{e} \_\mathrm{p}}\right)^{2}= & \frac{1}{2}\left(2 \overrightarrow{\nabla_{\mathrm{i}}} \ln \left(\psi_{\mathrm{ip}}^{\mathrm{e} \_\mathrm{p}}\right) \overrightarrow{\nabla_{\mathrm{i}}} \ln \varphi_{\mathrm{e}}+2 \overrightarrow{\nabla_{\mathrm{i}}} \ln \left(\psi_{\mathrm{ip}}^{\mathrm{e}-\mathrm{p}}\right) \vec{\nabla}_{\mathrm{i}} \sum_{\substack{\mathrm{j}=1 \\
\mathrm{j} \neq \mathrm{i}}}^{6} \ln \left(\psi_{\mathrm{ij}}^{\mathrm{e}-\mathrm{e}}\right)+\left[\overrightarrow{\nabla_{\mathrm{i}}} \ln \left(\psi_{\mathrm{ip}}^{\mathrm{e}-\mathrm{p}}\right)\right]^{2}\right) \\
\left(\mathrm{F}_{\mathrm{p}}^{\mathrm{e}-\mathrm{p}}\right)^{2}= & \frac{1}{2}\left(2 \overrightarrow{\nabla_{\mathrm{p}}}\left(\sum_{\mathrm{i}=1}^{6} \ln \left(\psi_{\mathrm{ip}}^{\mathrm{e} \_\mathrm{p}}\right)\right) \overrightarrow{\nabla_{\mathrm{p}}} \ln \left(\psi_{\mathrm{p}}\right)+\left[\overrightarrow{\nabla_{\mathrm{p}}}\left(\sum_{\mathrm{i}=1}^{6} \ln \left(\psi_{\mathrm{ip}}^{\mathrm{e}-\mathrm{p}}\right)\right)\right]^{2}\right) \\
\mathrm{V}^{\mathrm{e} \_\mathrm{p}} & =-\sum_{\mathrm{i}=1}^{6} \frac{1}{\left|\mathrm{r}_{\mathrm{ip}}\right|}
\end{aligned}
$$

\section{CALCULATING}

In calculation, we will generate 8 sets of data by varying one of the eight parameters $\lambda_{\mathrm{Zn}}$, $\lambda_{\mathrm{O}}, \alpha, \beta, \lambda_{\mathrm{pZn}}, \lambda_{\mathrm{pO}}, \alpha^{\prime}, \beta^{\prime}$ and keeping the other seven parameters as constants. Runs were performed with $\mathrm{N}=300$ walkers and MCSteps $=10000$ times (Monte Carlo steps).

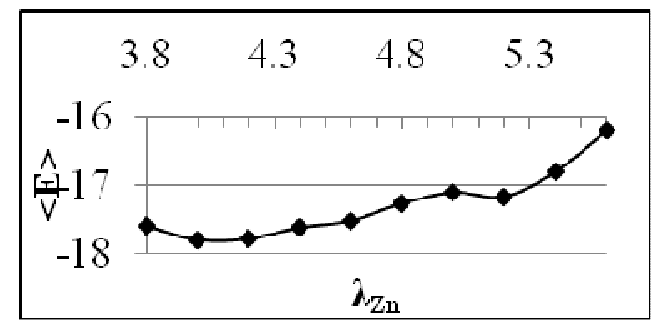

Fig.2a. The average energy is in the term of $\lambda_{\mathrm{Zn}}$

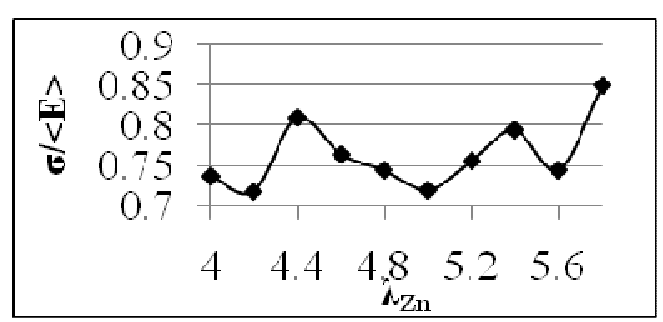

Fig.2b. The relative error is in the term of $\lambda_{\mathrm{Zn}}$

Varying the parameter $\lambda_{\mathrm{Zn}}$ : First, we will vary the parameter $\lambda_{\mathrm{Zn}}$ from $\lambda_{\mathrm{ZnMin}}=3$ to $\lambda_{\mathrm{ZnMax}}$ $=6.8$ with $\delta \lambda_{\mathrm{Zn}}=0.2$ while $\lambda_{\mathrm{O}}=3.2, \alpha=0.14$, $\beta=0.5, \lambda_{\mathrm{pZn}}=0.21, \lambda_{\mathrm{pO}}=0.72, \alpha^{\prime}=0.88$ and $\beta^{\prime}$ $=-1.5$ are considered as constants. The following plots show results for the average energy $\langle E\rangle$ and its relative error as functions of the variational parameter $\lambda_{\mathrm{Zn}}$.

The average energy and the relative error is minimum at $\lambda_{\mathrm{Zn}}=4.2$ which corresponds to the optimized solution for the ground state.

Varying the parameter $\lambda_{0}$ : Second, we will vary the parameter $\lambda_{0}$ from $\lambda_{\text {OMin }}=4$ to $\lambda_{\text {OMax }}=$ 6.8 with $\delta \lambda_{0}=0.2$ while $\lambda_{\mathrm{Zn}}=4.2, \alpha=0.14, \beta$ $=0.5, \lambda_{\mathrm{pZn}}=0.21, \lambda_{\mathrm{pO}}=0.72, \alpha^{\prime}=0.88$ and $\beta^{\prime}$ $=-1.5$ are considered as constants. The following plots show results for the average energy $\langle E\rangle$ and its relative error as functions of the variational parameter $\lambda_{\mathrm{O}}$.

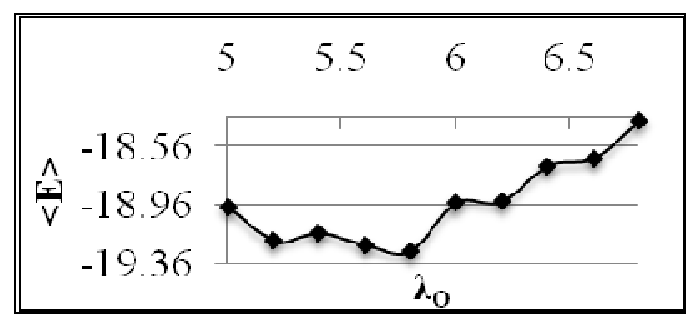

Fig.3a. The average energy is in the term of $\lambda_{O}$ 


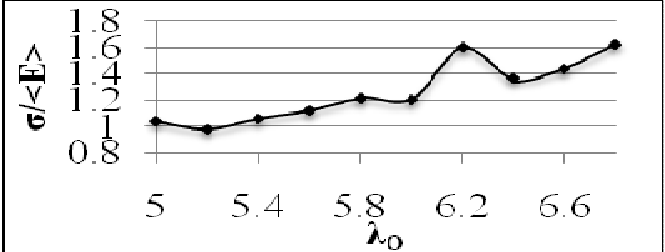

Fig.3b. The relative error is in the term of $\lambda_{\mathrm{O}}$

The average energy and the relative error is minimum at $\lambda_{\mathrm{O}}=5.2$ which corresponds to the optimized solution for the ground state.

Varying the parameter $\beta$ : Next, we will vary the parameter $\beta$ from $\beta_{\text {Min }}=0.32$ to $\beta_{\text {Max }}=$ 0.7 with $\delta \beta=0.02$ while $\lambda_{\mathrm{O}}=5.2, \lambda_{\mathrm{Zn}}=4.2, \alpha$ $=0.14, \lambda_{\mathrm{pZn}}=0.21, \lambda_{\mathrm{pO}}=0.72, \alpha^{\prime}=0.88$ and $\beta^{\prime}$ $=-1.5$ are considered as constants. The following plots show results for the average energy $\langle\mathrm{E}\rangle$ and its relative error as functions of the variational parameter $\beta$.

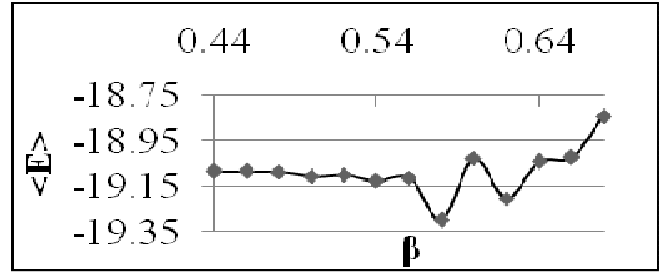

Fig.4a. The average energy is in the term of $\beta$

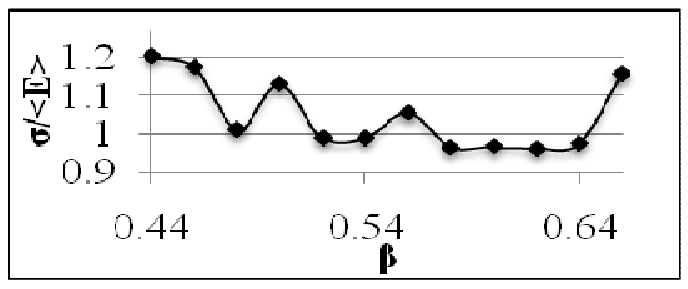

Fig.4b. The relative error is in the term of $\beta$

The average energy and the relative error is minimum at $\beta=0.58$ which corresponds to the optimized solution for the ground state.

Varying the parameter $\alpha$ : Next, we will vary the parameter $\alpha$ from $\alpha_{\text {Min }}=0.06$ to $\alpha_{\text {Max }}=$
0.48 with $\delta \alpha=0.02$ while $\lambda_{\mathrm{O}}=5.2, \lambda_{\mathrm{Zn}}=4.2, \beta$ $=0.58, \lambda_{\mathrm{pZn}}=0.21, \lambda_{\mathrm{pO}}=0.72, \alpha^{\prime}=0.88$ and $\beta^{\prime}$ $=-1.5$ are considered as constants. The following plots show results for the average energy $\langle E\rangle$ and its relative error as functions of the variational parameter $\alpha$.

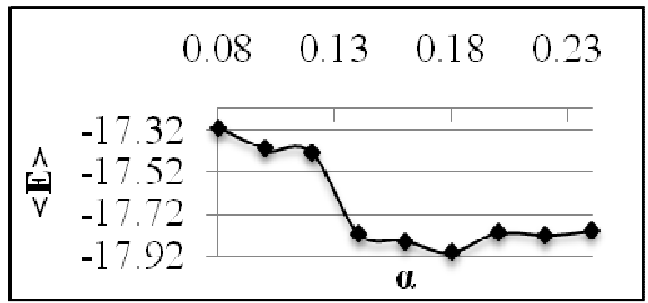

Fig.5a. The average energy is in the term of $\alpha$

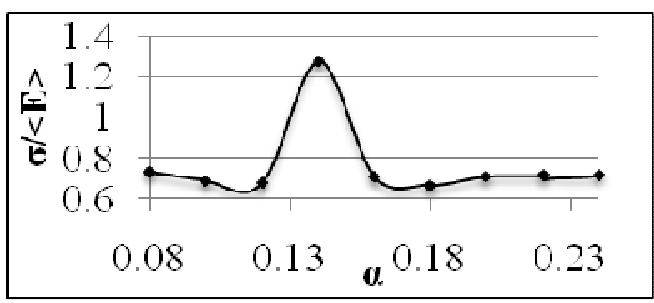

Fig.5b. The relative error is in the term of $\alpha$

The average energy and the relative error is minimum at $\alpha=0.18$ which corresponds to the optimized solution for the ground state.

Varying the parameter $\lambda_{\mathrm{pZn}}$ : Next, we will vary the parameter $\lambda_{\mathrm{pZn}}$ from $\lambda_{\mathrm{pZnMin}}=0.06$ to $\lambda_{\text {pZnMax }}=0.48$ with $\delta \lambda_{\mathrm{pZn}}=0.02$ while $\lambda_{\mathrm{Zn}}=4.2$, $\lambda_{\mathrm{O}}=5.2, \alpha=0.18, \beta=0.58, \lambda_{\mathrm{pO}}=0.72, \alpha^{\prime}=$ 0.88 and $\beta=-1,5$ are considered as constants. The following plots show results for the average energy $\langle E\rangle$ and its relative error as functions of the variational parameter $\lambda_{\mathrm{pZn}}$.

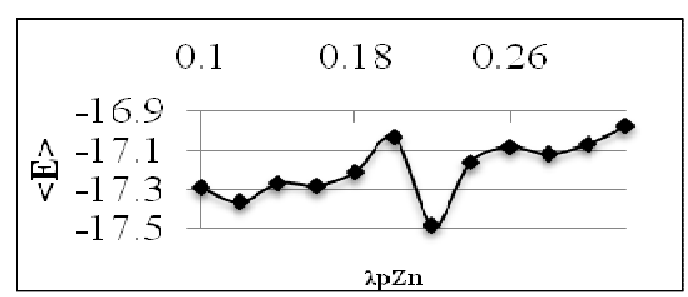


Fig.6a. The average energy is in the term of $\lambda_{\mathrm{pZn}}$

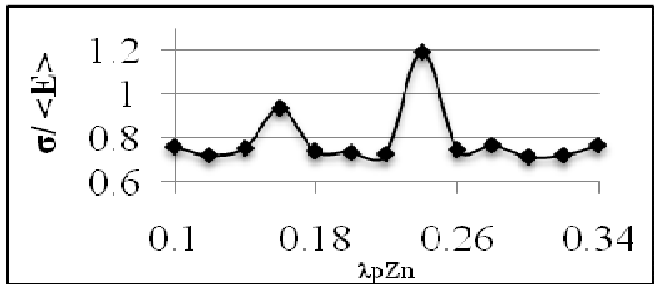

Fig.6b. The relative error is in the term of $\lambda_{\mathrm{Zn}}$

The average energy and the relative error is minimum at $\lambda_{\mathrm{pZn}}=0.22$ which corresponds to the optimized solution for the ground state.

Varying the parameter $\lambda_{\mathrm{po}}$ : Next, we will vary the parameter $\lambda_{\mathrm{pO}}$ from $\lambda_{\mathrm{pOMin}}=0.1$ to $\lambda_{\text {pOMax }}=0.48$ with $\delta \lambda_{\mathrm{pO}}=0.02$ while $\lambda_{\mathrm{Zn}}=4.2$, $\lambda_{\mathrm{O}}=5.2, \alpha=0.18, \beta=0.58, \lambda_{\mathrm{pZn}}=0.22, \alpha^{\prime}=$ 0.88 and $\beta=-1,5$ are considered as constants. The following plots show results for the average energy $\langle\mathrm{E}\rangle$ and its relative error as functions of the variational parameter $\lambda_{\mathrm{pO}}$.

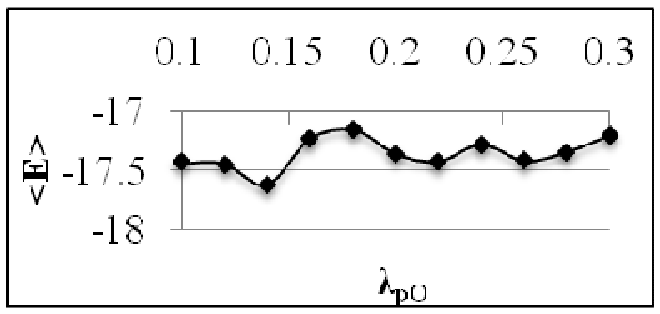

Fig.7a. The average energy is in the term of $\lambda_{\mathrm{pO}}$

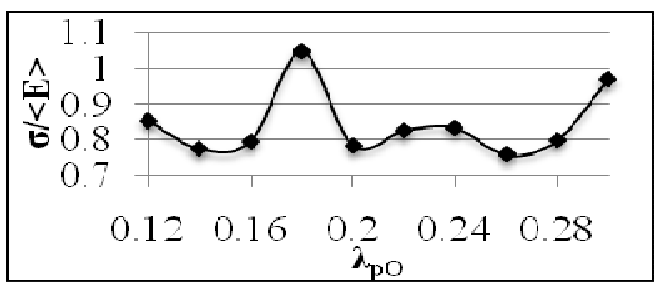

Fig.7b. The relative error is in the term of $\lambda_{p O}$

The average energy and the relative error is minimum at $\lambda_{\mathrm{pO}}=0.14$ which corresponds to the optimized solution for the ground state.
Varying the parameter $\beta^{\prime}$ : Next, we will vary the parameter $\beta^{\prime}$ from $\beta_{\text {Min }}^{\prime}=0.02$ to $\beta_{\text {Max }}^{\prime}$ $=0.38$ with $\delta \beta^{\prime}=0.02$ while $\lambda_{\mathrm{Zn}}=4.2, \lambda_{\mathrm{O}}=5.2$, $\alpha=0.18, \beta=0.58, \lambda_{\mathrm{pZn}}=0.22, \lambda_{\mathrm{pO}}=0.14$ and $\alpha^{\prime}=0.88$ are considered as constants. The following plots show results for the average energy $\langle E\rangle$ and the variance as functions of the variational parameter $\beta$ '.

The average energy and the relative error is minimum at $\beta^{\prime}=0.04$ which corresponds to the optimized solution for the ground state.

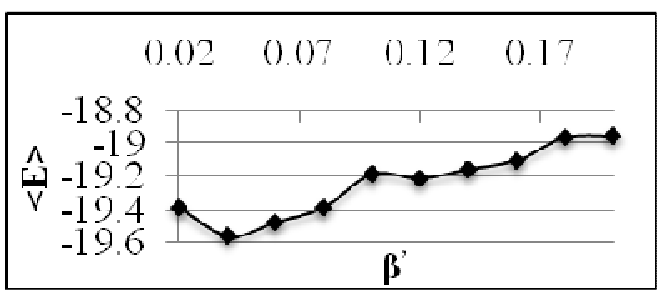

Fig.8a. The average energy is in the term of $\beta$ '

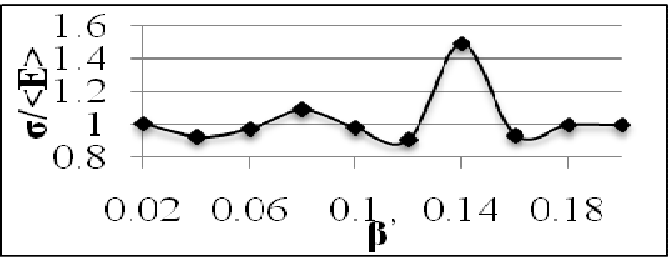

Fig.8b. The relative error is in the term of $\beta$

Varying the parameter $\alpha$ : Next, we will vary the parameter $\alpha$ from $\alpha_{\text {Min }}=0.2$ to $\alpha_{\text {Max }}=$ 0.38 with $\delta \alpha=0.2$ while $\lambda_{\mathrm{Zn}}=4.2, \lambda_{\mathrm{O}}=5.2, \alpha$ $=0.18, \beta=0.58, \lambda_{\mathrm{pZn}}=0.22, \lambda_{\mathrm{pO}}=0.14$ and $\beta$, $=0.04$ are considered as constants. The following plots show results for the average energy $\langle E\rangle$ and its relative error as functions of the variational parameter $\alpha$.

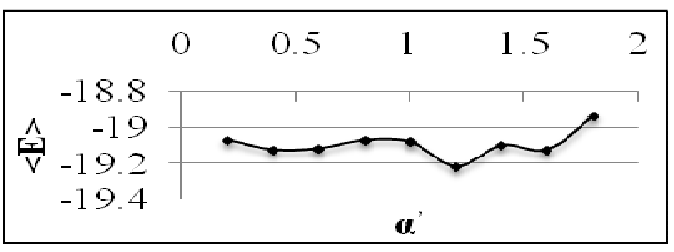


Fig.9a. The average energy is in the term of $\alpha$

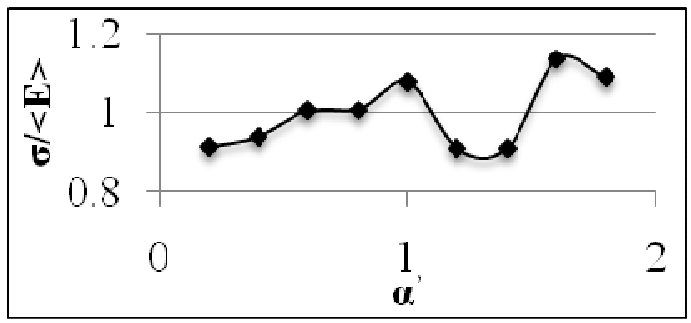

Fig.9b. The relative error is in the term of $\alpha$

The average energy and the relative error is minimum at $\alpha=1.2$ which corresponds to the optimized solution for the ground state.

Finally, we get the values of the optimized parameters listed in the following table 1

Table 1. The values of exact parameters

\begin{tabular}{|c|c|c|c|c|c|c|c|}
\hline$\lambda_{\mathrm{O}}$ & $\lambda_{\mathrm{Zn}}$ & $\alpha$ & $\beta$ & $\lambda_{\mathrm{pZn}}$ & $\lambda_{\mathrm{pO}}$ & $\alpha$ & $\beta$ \\
\hline 5.2 & 4.2 & 0.18 & 0.58 & 0.22 & 0.14 & 1.2 & 0.04 \\
\hline
\end{tabular}

After varying alternately the parameters, we continuous to estimate the correlation energy $E^{\mathrm{e}-\mathrm{p}}$ with the set of the optimized parameters by applying to the formula (18) and the result is $\mathrm{E}^{\mathrm{e}-\mathrm{p}}=-9.3 \pm 1.1(\mathrm{eV})$.

\section{CONCLUSION}

In this article, we described the Variational Quantum Monte Carlo method, the technique that was used to estimate the value of the electron, positron correlation - energy of $\mathrm{ZnO}$ molecule. The Hamiltonian and the many electron, positron wave function were also discussed.

With building a code based on programming language $\mathrm{C}++$, performing the configuration with 300 walkers and 10000 MCSteps, the electron, positron correlation energy of $\mathrm{ZnO}$ molecule was estimated, $\mathrm{E}^{\mathrm{e}-\mathrm{p}}=$ $9.3 \pm 1.1(\mathrm{eV})$. It turns out that the value is closer to results estimated by other methods [2] than the value that we had done before. 


\title{
KHẢO SÁT NĂNG LƯợNG TƯƠNG QUAN ELECTRON - POSITRON TRONG ZnO VớI SỬ HIỆU CHỈNH HÀM SÓNG POSITRON
}

\author{
Châu Văn Tạo ${ }^{(1)}$, Trịnh Hoa Lăng ${ }^{(1)}$, \\ Nguyễn Anh Tuấn ${ }^{(2)}$, Lê Hoàng Chiến ${ }^{(1)}$, Nguyễn Hũu Lộc \\ (1) Trường Đại học Khoa học Tự nhiên \\ (2) Trung tâm Nghiên cứu và Triển khai Công nghệ Bức xạ
}

TÓM TĂT: Trong bài báo này, chúng tôi tính năng luợng tuơng quan electron - positron trong phân tử kẽm oxit (ZnO), trong đó giả thiết rằng positron liên kết với các electron thuộc phân lớp ngoài cùng của các nguyên tử kẽm và oxi truớc khi nó hủy với một trong các electron đó. Với việc sử dụng phuong pháp biến phân Monte - Carlo luợng tư (VQMC), đồng thời hiệu chỉnh hàm sóng của positron theo nguyên lý chồng chất nhiều trạng thái, năng luợng tuoong quan electron-positron được tính toán và nó có giá trị là $E_{c}^{e-p}=-9,3 \pm 1,1 \mathrm{eV}$. Kết quả này $(-9,3 \mathrm{eV})$ gần với các kết quả của một số chất được tính bởi các phuoong pháp khác hơn so với truờng hợp mà chúng tôi đã tính truớc đây.

Từ khóa: Positron, biến phân Monte - Carlo lượng tử

\section{REFERENCES}

[1]. Louisa Màiri Fraser, Coulomb interactions and Positron annihilation in many fermion systems: A Monte Carlo approach, Thesis submitted for the degree of Doctor of Philosophy of the University of London and the Diploma of Imperial College, Technology and Medicine London (9/1995).
[2]. M. J. Puska and R. M. Nieminen, Defect spectroscopy with positron: a general calculation method, J. Phys. F: Met. Phys, 333-346 (1983).

[3]. N. W. Ashcroft and N. D. Mermin, Solid State Physics, (Holt-Saunders, 1976).

[4]. Valerio Magnasco, Methods of Molecular Quantum Mechanics, University of Genoa, Genoa, Italy (2009). 